\title{
Continuous Infusion Versus Intermittent Bolus Furosemide in ADHF: An Updated Meta-Analysis of Randomized Control Trials
}

\author{
Muhammad Amer, $\mathrm{MD}^{1 *}$, Jurga Adomaityte, $\mathrm{MD}^{2}$, Rehan Qayyum, MD, MHS ${ }^{1}$
}

'Division of General Internal Medicine/Hospitalist Program, Johns Hopkins School of Medicine, Baltimore, Maryland; '2Sinai/Johns Hopkins University Internal Medicine Residency Program, Sinai Hospital of Baltimore, Baltimore, Maryland.

OBJECTIVE: Administering intermittent boluses of furosemide to patients with acute decompensated heart failure (ADHF) often leads to unfavorable hemodynamic changes. Continuous infusion may induce similar or greater diuresis without adverse hemodynamic consequences. We conducted a systemic review and meta-analysis of randomized clinical trials that compared the effects of continuous infusion and intermittent bolus of furosemide in patients hospitalized with ADHF.

METHODS: We searched PubMed, EMBASE, and The Cochrane Central Register of Controlled Trials databases from their inception until March 2011. Two investigators independently abstracted data on study characteristics, quality, and selected outcomes. Differences between investigators were resolved by mutual consensus. Comparisons were reported as the weighted mean difference (WMDs).

RESULTS: Ten trials involving a total of 564 patients were included. When administered as a continuous infusion, furosemide resulted in greater diuresis (WMD, -240.54 mL/ 24 hours/100 mg furosemide; 95\% confidence interval [Cl], -462.42 to -18.66$)$ and reduction in total body weight (WMD, $-0.78 \mathrm{~kg} ; 95 \% \mathrm{Cl},-1.54$ to -0.03 ), than when administered in intermittent boluses. Urinary sodium excretion (WMD, -20.26 mmol/24 hours; 95\% Cl, -60.48 to 19.96) and duration of hospital stay (WMD, 0.99 days; $95 \% \mathrm{Cl},-2.08$ to 4.06 ) were not different between the 2 groups.

CONCLUSION: This meta-analysis showed statistical support for administering furosemide as a continuous infusion for greater diuresis and reduction in total body weight in patients hospitalized with ADHF. With the exception of greater diuresis, available data are homogenous for the reported outcomes but lack information on clinical endpoints. Larger studies are needed to provide robust recommendations for clinical practice. Journal of Hospital Medicine 2012;7:270-275. ( ) 2011 Society of Hospital Medicine.
Acute decompensated heart failure (ADHF) is the most common cause of hospitalization among adults in the United States and is associated with high morbidity and mortality. ${ }^{1}$ The estimated direct and indirect cost of ADHF management in the United States was $\$ 40$ billion in $2010 .^{1}$ There are approximately 5.7 million patients with heart failure in the United States with an annual mortality rate of 300,000 deaths per year. ${ }^{2}$ The Healthcare Cost and Utilization Project reported 1.1 million hospital admissions, an average hospital stay of 5.5 days, and $4 \%$ in-hospital mortality for patients with heart failure in $2004 .^{3}$

Intravenous administration of loop diuretics is the mainstay of treatment of volume overload in patients hospitalized with ADHF. ${ }^{4}$ However, when adminis-

\footnotetext{
*Address for correspondence and reprint requests: Muhammad Amer, MD, Johns Hopkins University Hospital, 600 North Wolfe Street, Park 300, Baltimore, MD 21287; Tel.: 443-287-3631/410-502-2128; Fax: 410-502-0923; E-mail: mamer1@jhmi.edu

Additional Supporting Information may be found in the online version of this article.

Received: March 10, 2011; Revised: September 11, 2011; Accepted: September 22, 2011

2011 Society of Hospital Medicine DOI 10.1002/jhm.991

Published online in Wiley Online Library (Wileyonlinelibrary.com).
}

tered as intermittent bolus injections, loop diuretics usually lead to rapid intravascular volume changes, ${ }^{5}$ significant electrolyte abnormalities, ${ }^{6,7}$ renal dysfunction, ${ }^{8,9}$ and undesired neurohormonal activity. ${ }^{10,11}$ Compared with intermittent bolus injections, continuous infusion of loop diuretics may induce a more sustained and greater diuresis and fewer electrolyte abnormalities. ${ }^{12-16}$ Several studies of limited duration have compared the effectiveness of the 2 routes of intravenous administration of loop diuretics; however, the results of these studies are contradictory. ${ }^{13,14,17,18}$ In a meta-analysis, Salvador et $\mathrm{al}^{19}$ compared the effectiveness of continuous infusion and intermittent bolus injections of loop diuretics. The authors reported greater diuresis (measured as 24-hour urinary output) in patients receiving continuous infusion of loop diuretics. However, the meta-analysis included studies that examined loop diuretics other than furosemide, ${ }^{20}$ allowed concomitant use of hypertonic saline infusions, ${ }^{21}$ and included patients with pulmonary edema from noncardiogenic causes. ${ }^{22}$

Furosemide is one of the most commonly used loop diuretics. ${ }^{23}$ The current literature lacks a systematic review and meta-analysis comparing the effectiveness of continuous infusion and intermittent bolus 
furosemide therapy among nonsurgical, hemodynamically stable, hospitalized patients with ADHF. In addition, several important randomized trials published in recent years comparing the effectiveness of the 2 routes of intravenous furosemide delivery warrant $^{17,24-27}$ systematic review, because the last published meta-analysis (by Salvador et $\mathrm{al}^{19}$ ) was in 2005 .

We therefore conducted a systematic review and meta-analysis of randomized controlled trials that compared the effects of continuous infusion and intermittent bolus of furosemide in patients hospitalized with ADHF.

\section{METHODS}

\section{Study Selection}

We searched the PubMed, EMBASE, and The Cochrane Central Register of Controlled Trials electronic databases systematically from their inception through March 2011 using the search terms lasix, furosemide, diuretic, congestive heart failure, infusion, and bolus. The electronic database search was supplemented by hand-searching bibliographies of the retrieved articles. Two investigators independently reviewed all retrieved articles for their eligibility based on predefined criteria. Disagreement on study selection was resolved by mutual consensus and by the involvement of a third investigator. All selected studies were assessed for content validity.

We included both crossover and parallel-arm randomized control trials. Studies were included if patients were randomized to intermittent bolus or continuous infusion of furosemide, and data were reported on 24-hour urinary volume, total body weight loss, 24-hour urinary sodium excretion, and duration of hospital stay. Randomized control trials that included patients with cardiogenic shock requiring concomitant vasopressor therapy, renal failure with or without hemodialysis, and loop diuretics other than furosemide were excluded. The primary authors of the included studies were contacted if the results of the selected outcomes either were not reported or required further clarification. A flow diagram was produced following guidelines from The Quality of Reporting of Meta-analyses (QUOROM) group $^{28}$ to provide information on randomized clinical trial identification for the final inclusion in the meta-analysis.

\section{Data Extraction}

Data on study design, participant characteristics, methods, intervention, and selected outcomes were independently extracted by 2 investigators. Interobserver agreement for full study selection was calculated using an unweighted kappa statistic. A chi-square test $\left(\chi^{2}\right)$ and $\mathrm{I}^{2}$ statistic were used to report the percentage of variability in the effect estimates across studies.

\section{Quality Assessment}

The quality of included trials was assessed using a validated scale developed by Jadad et $\mathrm{al}^{29}$ that assigns a score from 0 to 5 , with a higher score indicating higher quality. Two investigators independently evaluated studies on 3 parameters: randomization, blinding, and dropouts. The third investigator helped resolve discordant assessments. We assessed publication bias visually by examining the symmetry of funnel plots and statistically using Begg ${ }^{30}$ and Egger ${ }^{31}$ tests.

\section{Data Synthesis and Analysis}

For the reported outcomes, we recorded the mean difference between the groups and measures of dispersion. If a mean difference was not reported, we calculated point estimates by using the mean difference from baseline for each group. If a mean difference from baseline was not reported, we calculated point estimates using the baseline and final value for each group. If a measure of dispersion was not reported for the between-group difference, we calculated it by using the sum of the variance for the mean difference from baseline in each group. If no measure of dispersion was reported for the mean difference from baseline for each group, we calculated variance by using the standard deviation of the baseline and final values, and assumed a correlation between the baseline and final values of 0.5 .

Urinary volume was measured in milliliters per 24 hours per $100 \mathrm{mg}$ furosemide to compare the diuretic effect between the 2 routes of intravenous administration. Total body weight loss was measured in kilograms. Urinary sodium was measured in millimoles per 24 hours, and duration of hospital stay was measured in days.

Weighted mean differences (WMDs) with 95\% confidence intervals (CIs) were calculated for all prespecified outcomes using Review Manager (RevMan) Version 5.0. Copenhagen: The Nordic Cochrane Centre, The Cochrane Collaboration, 2008. We pooled results from individual studies using a random-effects model. Statistical significance was set at $P \leq 0.05$ using a 2tailed Z-test. Sensitivity analyses were conducted by omitting one study at a time for all outcomes.

\section{RESULTS}

\section{Study Selection}

We identified 104 studies using the previously stated search terms. Following QUOROM guidelines, ten randomized clinical trials, enrolling a total of 564 patients, fulfilled the inclusion criteria (Figure 1). The interobserver agreement (unweighted kappa statistic) between investigators for study selection was 0.75 .

\section{Study Characteristics}

The majority of patients were male $(60 \%)$ with a mean age of 62.8 years (range $54-74.1$ years). The 
duration of follow-up while on furosemide in both arms ranged from twelve hours ${ }^{24}$ to six days ${ }^{13}$ (Table 1). We found significant variability in dose, frequency, and duration of treatment across studies for both routes of intravenous furosemide administration (Table 2). Four of 10 studies were crossover trials $^{13,14,18,32}$ and the rest were parallel-arm trials. Randomization to 1 of the 2 treatment groups was reported in all 4 crossover trials.

\section{Outcomes}

Data on 24-hour urinary volume were reported in all 10 studies. We found that the continuous infusion of

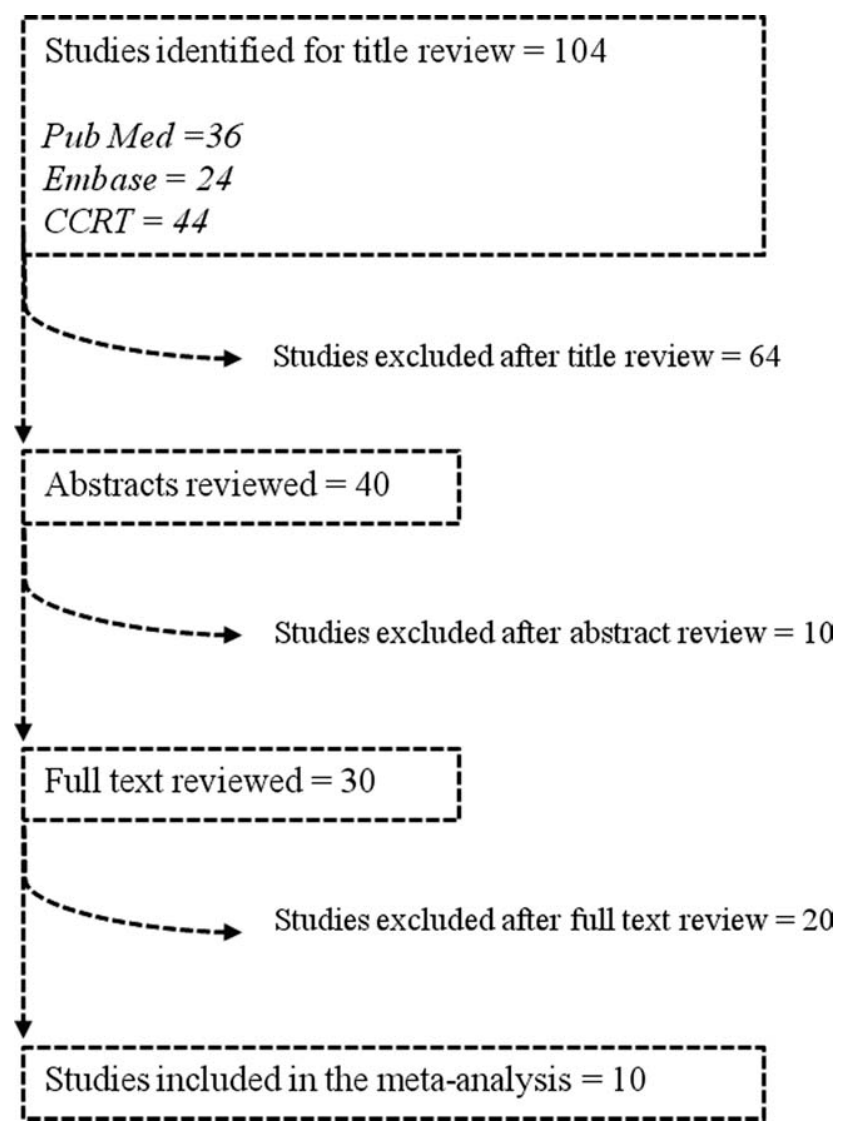

FIG. 1. Quality of Reporting of Meta-analysis (QUOROM) flow chart. CCRT: The Cochrane Central Register of Controlled Trials. furosemide was associated with a statistically significant increase in 24-hour urinary output compared with intermittent bolus injections (WMD, -240.54 $\mathrm{mL} / 24$ hours $/ 100 \mathrm{mg}$ furosemide; $95 \%$ CI, -462.42 to $-18.66 ; P=0.03)$. There was evidence of statistically significant heterogeneity between the studies for the outcome of 24-hour urinary volume $\left(\mathrm{I}^{2}=89 \%\right.$; $\chi^{2}=93.11 ; P<0.001$ ) (Figure 2). The magnitude of statistical heterogeneity decreased $\left(\mathrm{I}^{2}=53 \% ; \chi^{2}=\right.$ $19.11 ; P=0.02$ ) but remained significant after removing a study by Ostermann et al. ${ }^{26}$

Data on total body weight loss was reported in 3 parallel trials. Patients treated with a continuous infusion of furosemide had statistically greater changes in total body weight (WMD, $-0.78 \mathrm{~kg} ; 95 \% \mathrm{CI},-1.54$ to $-0.03 ; P=$ 0.04 ) when compared with patients receiving bolus injections of furosemide. Data for total body weight loss were collected at 72 hours of treatment in 2 trials ${ }^{17,27}$ and was reported for the duration of the entire study by Thomson et al. ${ }^{25}$ There was no statistical evidence of heterogeneity between the studies for total body weight loss $\left(\mathrm{I}^{2}=0 \%\right.$; $\chi^{2}=0.66 ; P=0.72$ ) (Figure 3).

Data on 24-hour urinary sodium excretion was reported for 57 patients in the 4 crossover studies. A continuous infusion of furosemide was associated with a statistically insignificant increase in 24-hour urinary sodium (WMD, $-20.26 \mathrm{mmol} / 24$ hours; 95\% CI, -60.48 to $19.96 ; P=0.32)$. There was no statistical evidence of heterogeneity between studies for 24-hour urinary sodium excretion $\left(\mathrm{I}^{2}=0 \% ; \chi^{2}=2.76 ; P=0.60\right)$ (Figure 2).

Duration of hospital stay was reported in 3 parallel trials. Patients receiving intermittent injections of bolus furosemide had longer hospital stays (WMD, 0.99 days; $95 \% \mathrm{CI},-2.08$ to $4.06 ; P=0.53$ ), but this difference was not statistically significant. There was no evidence of heterogeneity between the studies for the duration of hospital stay $\left(\mathrm{I}^{2}=64 \% ; \chi^{2}=\right.$ 5.51; $P=0.06$ ) (Figure 3).

\section{Risk of Bias and Sensitivity Analysis}

Individual quality assessment scores based on a scoring system developed by Jadad et $\mathrm{a}^{29}$ for included trials are reported (Table 1). Randomization was

TABLE 1. Characteristics of Studies Included in the Meta-analysis

\begin{tabular}{|c|c|c|c|c|c|c|c|c|}
\hline Study & Study Design* & Total (N) & Mean Age (years) & Male (n) & $\begin{array}{l}\text { Duration on } \\
\text { Furosemide (days) }\end{array}$ & Country of Study & NYHA Class & Jadad Quality Score \\
\hline Aaser et al ${ }^{18}$ & $\mathrm{CO}$ & 8 & 54 & 6 & 2 & Norway & ||I-IV & 1 \\
\hline Allen et $\mathrm{al}^{17}$ & PA & 41 & 61 & 26 & 2 & USA & NR & 3 \\
\hline Dormans et $\mathrm{al}^{13}$ & $\mathrm{CO}$ & 20 & 71 & 13 & 6 & Netherlands & $\|||-\mid V$ & 1 \\
\hline Felker et al ${ }^{27}$ & $\mathrm{PA}$ & 308 & 66 & 226 & 3 & USA & NR & 4 \\
\hline Lahav et al ${ }^{14}$ & $\mathrm{CO}$ & 9 & 74.1 & 5 & 4 & Israel & |II-IV & 1 \\
\hline Mojtahedzadeh et al ${ }^{33}$ & PA & 22 & NR & NR & 1.5 & Iran & NR & 2 \\
\hline Mojtahedzadeh et al ${ }^{24}$ & $\mathrm{PA}$ & 21 & 56.5 & 11 & 0.5 & $\operatorname{lran}$ & NR & 2 \\
\hline Ostermann et al ${ }^{26}$ & PA & 59 & 64 & 31 & 2 & UK/Canada & NR & 3 \\
\hline Pivac et al ${ }^{32}$ & $\mathrm{CO}$ & 20 & 62.2 & 9 & 3 & Croatia & $\| \mid$ & 1 \\
\hline Thomson et al| ${ }^{25}$ & PA & 56 & 56.4 & 32 & $3.5-4.6$ & USA & ||$|-| V$ & 3 \\
\hline
\end{tabular}

Abbreviations: CO, crossover; NR, not reported; NYHA, New York Heart Association; PA, parallel-arm. 
TABLE 2. Furosemide Dosing from Studies Included in the Meta-analysis

\begin{tabular}{|c|c|c|c|}
\hline \multirow[b]{2}{*}{ Study } & \multicolumn{2}{|c|}{ Furosemide Dose (Mean \pm SD) } & \multirow[b]{2}{*}{ Additional Comments } \\
\hline & Intermittent Bolus & Continuous Infusion & \\
\hline Aaser et al ${ }^{18}$ & $145 \pm 80 \mathrm{mg}$ bid & $145 \pm 80 \mathrm{mg} / 24 \mathrm{hr}$ & Furosemide dose was same as usual daily oral dose \\
\hline Allen et $\mathrm{al}^{17}$ & $162 \pm 48 \mathrm{mg}$ bid & $162 \pm 52 \mathrm{mg} / 24 \mathrm{hr}$ & Dose was determined by attending physician after enrollement \\
\hline Dormans et al ${ }^{13}$ & Single bolus of continous dose & $690 \mathrm{mg} / 8 \mathrm{hr}(250-2000 \mathrm{mg})$ & Patients received additional single oral doses of furosemide on first and second day \\
\hline Felker et a| ${ }^{27}$ & $134 \pm 53 \mathrm{mg} / \mathrm{day}$ & $127 \pm 50 \mathrm{mg} / \mathrm{day}$ & $\begin{array}{l}\text { Treatment was continued for up to } 72 \text { hours; at } 48 \text { hours, the treating physician had the } \\
\text { option of adjusting the diurtetic dose on the basis of clinical response }\end{array}$ \\
\hline Lahav et al ${ }^{14}$ & $30-40 \mathrm{mg} / 8 \mathrm{hr}$ & $60-80 \mathrm{mg} / 24 \mathrm{hr}$ & Continuous group received 30-40 mg bolus furosemide as loading dose \\
\hline Mojtahedzadeh et al ${ }^{33}$ & $320 \mathrm{mg} / \mathrm{dose}$ & $0.75 \mathrm{mg} / \mathrm{kg} / \mathrm{hr}$ & All patients received $20 \mathrm{mg}$ of furosemide as initial bolus in both arms \\
\hline Mojtahedzadeh et $\mathrm{al}^{24}$ & $20 \mathrm{mg}$ initial, then doubled every $3 \mathrm{hr} *$ & $0.1 \mathrm{mg} / \mathrm{kg} / \mathrm{hr}$ (total $250 \mathrm{mg}$ ) & Both regimens were titrated for a goal net fluid balance of at least $1 \mathrm{~mL} / \mathrm{kg} / \mathrm{hr}$ \\
\hline Ostermann et al ${ }^{26}$ & $0.6-5.14 / \mathrm{kg} / \mathrm{dose}$ & $0.4-0.6 \mathrm{mg} / \mathrm{kg} / \mathrm{hr}$ & Predefined alogrithms aiming for minimum hourly urine output was used in both arms \\
\hline Pivac et a $\left.\right|^{32}$ & $40 \mathrm{mg}$ bid & $40 \mathrm{mg}$ bid & Goal was to increase urine output to at least $50 \%$ from baseline or a minimum of $1 \mathrm{~mL} / \mathrm{kg} / \mathrm{hr}$ \\
\hline Thomson et al ${ }^{25}$ & $172 \pm 97 \mathrm{mg}$ & $197 \pm 148 \mathrm{mg} / \mathrm{day}$ & The mean duration of study drug administration was shorter by approximately 1 day in the continous group \\
\hline
\end{tabular}

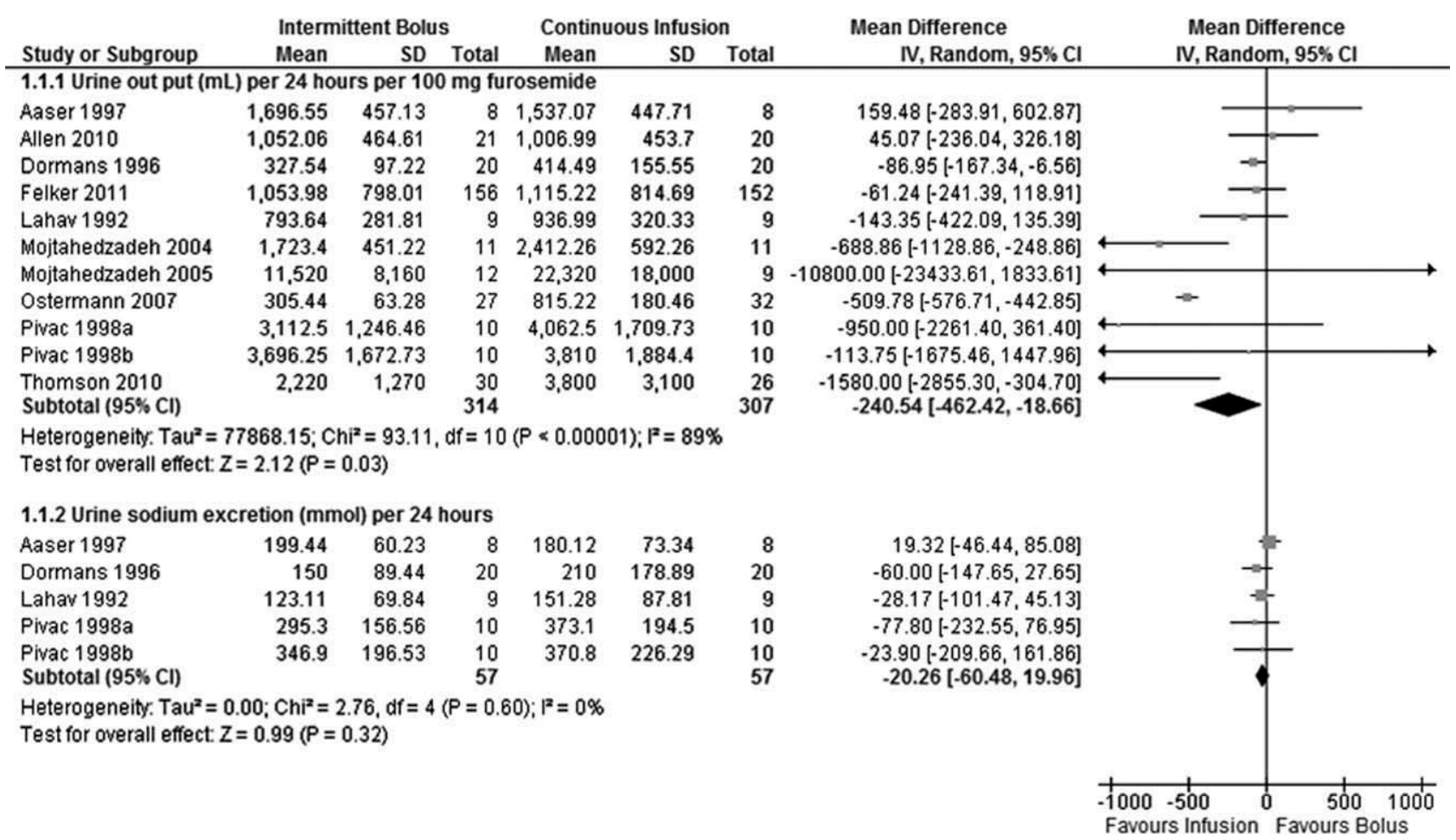

FIG. 2. Mean differences in 24-hour urinary volume $(\mathrm{mL})$ and urinary sodium excretion (mmol) in patients treated with intermittent bolus and continuous infusion of furosemide.

reported by all studies, but the explicit methodology of randomization was defined in only 4 studies. ${ }^{17,25-27}$ Allocation concealment was defined in 1 study. ${ }^{26}$ Dropouts were reported in 4 studies. ${ }^{24-26,33}$ Adherence to intervention per study protocol was not reported in any of the selected studies. Three studies mentioned intention to treat. ${ }^{25,26}$ Sensitivity analyses demonstrated that the direction of the mean estimates did not change for any of the 4 outcomes when individual studies were excluded.

\section{DISCUSSION}

Our meta-analysis of 10 randomized, controlled clinical trials found that continuous infusion of furosemide results in significantly greater diuresis and reduction in total body weight than intermittent boluses in patients hospitalized with ADHF. No statistical differences were observed in urinary sodium excretion or the duration of hospital stay between the 2 routes of intravenous furosemide administration. The data on greater diuresis from the available clinical trials was widely heterogeneous that may limit the merits of assessment of greater diuresis between the 2 methods of intravenous furosemide administration. In addition, data on clinical outcomes such as rates of rehospitalization, cardiovascular, and all-cause mortality were not reported in the studies selected for this metaanalysis.

The mean effective dose of loop diuretics administered as intermittent boluses varies widely ${ }^{5}$ and 


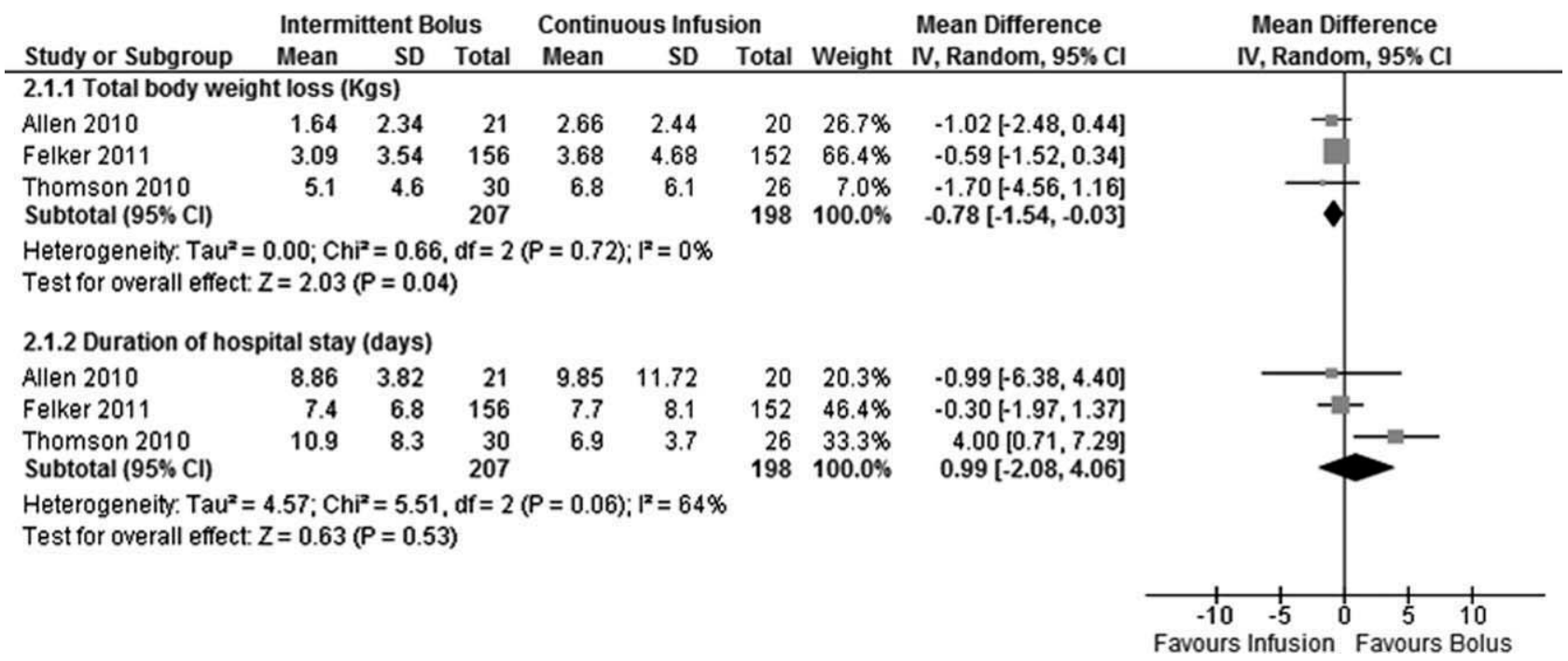

FIG. 3. Mean differences in total body weight loss (kg) and duration of hospital stay (days) in patients treated with intermittent bolus and continuous infusion of furosemide.

quickly dissipates to a level that fails to block $\mathrm{Na}^{+}$ reabsorption in renal tubules. ${ }^{34}$ Additionally, the effectiveness of loop diuretics is limited by the rebound in sodium reabsorption during periods of subtherapeutic renal tubular concentration because of their short half-life. ${ }^{4,6,35}$ It is possible that the ineffectiveness of subtherapeutic tubular filtrate levels of loop diuretics toward the end of a dosing interval when administered as a bolus is responsible for their unsustained diuretic effects. Bolus injections of furosemide have been associated with diuretic tolerance, reduced short-term natriuresis, and a probable rise in plasma aldosterone levels in the settings of salt restriction. ${ }^{36}$ Data from physiological studies suggest that greater diuresis, which also results in weight loss with continuous infusion of loop diuretics, is due to the minimal variation in the mean effective dose of drug in the renal tubules. ${ }^{12-16}$ By preventing subtherapeutic tubular dose concentrations, continuous infusion may limit rebound resorption helping to improve symptoms of $\mathrm{ADHF} .{ }^{4}$

Our study has several limitations. First, we examined only surrogate endpoints. Second, we included crossover trials ${ }^{13,14,18,32}$ in the analysis, and the variation in the washout periods of these trials may have affected the reported outcomes. The study by Aaser et $\mathrm{al}^{18}$ lacked a washout period because the authors were concerned for the hemodynamic stability of diuretic-dependent ADHF patients. Lahav et $\mathrm{al}^{14}$ reported a washout period of 3 hours, while Dormans et $\mathrm{al}^{13}$ and Pivac et $\mathrm{al}^{32}$ did not report the duration of washout periods. Finally, we excluded studies that enrolled postsurgical patients and patients with pulmonary edema from noncardiac causes. As a result, the generalizability of our findings is limited to relatively stable ADHF patients hospitalized because of medical, dietary, or pharmacological noncompliance. We re- stricted our analysis to studies using furosemide therapy only. By excluding trials using loop diuretics other than furosemide and trials reporting concomitant use of vasopressors or hypertonic saline in the study population, we are confident in the assessment of the isolated effects of furosemide for either route of its intravenous administration in patients hospitalized with ADHF.

The continuous infusion of furosemide has been well tolerated in most instances. ${ }^{13,25-27,32}$ Thomson et $\mathrm{al}^{25}$ found no difference on the incidence of significant hemodynamic changes or need for renal replacement therapy between the 2 groups. Similarly, Ostermann et $\mathrm{al}^{26}$ reported no significant differences in heart rate and mean arterial pressures changes from two treatment groups. In addition, Felker et $\mathrm{al}^{27}$ and Pivac et $\mathrm{al}^{32}$ found no differences in the proportion of serious adverse effects between the 2 routes of intravenous furosemide administration.

In the absence of information on clinical endpoints such as rehospitalization, all-cause mortality, and cardiovascular mortality, this meta-analysis could not settle the issue to provide definitive recommendations for treatment guidelines to use either route of intravenous furosemide in ADHF patients. However, it is important to note that despite different study populations, our finding of greater diuresis with continuous infusion of furosemide is consistent with results reported by Salvador et al. ${ }^{19}$ Given the higher prevalence, mortality, and significant cost related with ADHF management in the United States, we support the use of furosemide as a continuous infusion to ensure limited but established benefits, such as greater diuresis and reduction in total body weight,. This approach seems reasonable, especially when the safety profiles between the 2 treatment groups are not different. ${ }^{25-27,32}$ However, the benefits on surrogate outcomes cannot be 
overstressed due to lack of information on the costeffectiveness of furosemide or other loop diuretics administered as a continuous infusion.

\section{CONCLUSIONS}

We report a systematic review and meta-analysis comparing the effectiveness of 2 routes of intravenous furosemide administration in patients with ADHF. We found that continuous infusion of furosemide results in greater diuresis and greater reduction in total body weight. With the exception of greater diuresis, available data are homogenous for the reported outcomes in this meta-analysis. Due to lack of information on clinical endpoints and cost-effectiveness from currently available data, robust recommendations for clinical practice guidelines cannot be made at this time. Randomized controlled trials measuring hard clinical endpoints in larger patient populations may add stronger evidence to settle this issue in future. Further studies comparing cost-effectiveness related with continuous infusion of furosemide may provide critical information to establish it as the preferred route over intermittent bolus injection in clinical practice.

Disclosure: The authors have no conflicts of interest to report.

\section{References}

1. Lloyd-Jones D, Adams R, Carnethon M, et al. Heart disease and stroke statistics 2009 update: a report from the American Heart Association Statistics Committee and Stroke Statistics Subcommittee. Circulation. 2009;119:e21-e181.

2. National Heart, Lung, and Blood Institute. What Is Heart Failure? Available at: http://www.nhlbi.nih.gov/health/health-topics/topics/hf/ . Accessed March 6, 2011.

3. Russo CA, Ho K, Elixhauser A. Hospital Stays for Circulatory Diseases, 2004. Healthcare Cost and Utilization Project Statistical Brief No. 26. Rockville, MD: Agency for Healthcare Research and Quality; February 2007. Available at: http://www.hcup-us.ahrq.gov/reports/ statbriefs/sb26.jsp. Accessed February 22, 2010.

4. Jessup M, Abraham WT, Casey DE, et al. 2009 focused update: ACCF/AHA Guidelines for the Diagnosis and Management of Heart Failure in Adults: a report of the American College of Cardiology Foundation/American Heart Association Task Force on Practice Guidelines: developed in collaboration with the International Society for Heart and Lung Transplantation. Circulation. 2009;119: 1977-2016.

5. Branck RA, Roberts CJC, Homeida M, Levine D. Determinants of response to furosemide in normal subjects. $\mathrm{Br} J$ Clin Pharmacol. 1977;4:121-127.

6. Brater DC. Diuretic therapy. N Engl J Med. 1998;339:387-395.

7. Cooper HA, Dries DL, Davis CE, Shen YL, Domanski MJ. Diuretics and risk of arrhythmic death in patients with left ventricular dysfunction. Circulation. 1999;100:1311-1315.

8. Cotter G, Weissgarten J, Metzkor E, et al. Increased toxicity of high dose furosemide versus low-dose dopamine in the treatment of refractory congestive heart failure. Clin Pharmacol Ther. 1997;62: 187-193.

9. Butler J, Forman DE, Abraham WT, et al. Relationship between heart failure treatment and development of worsening renal function among hospitalized patients. Am Heart J. 2004:147:331-338.

10. Ikram H, Chan W, Espiner EA, Nicholls MG. Haemodynamic and hormone responses to acute and chronic furosemide therapy in congestive heart failure. Clin Sci. 1980;59:443-449.

11. Bayliss J, Norell M, Canepa-Anson R, Sutton G, Poole-Wilson P. Untreated heart failure: clinical and neuroendocrine effects of introducing diuretics. Br Heart J. 1987;57:17-22.
12. Kaojarern S, Day B, Brater DC. The time course of delivery of furosemide into urine: an independent determinant of overall response. Kidney Int. 1982;22:69-74.

13. Dormans TP, van Meyel JJ, Gerlag PG, Tan Y, Russel FG, Smits P. Diuretic efficacy of high dose furosemide in severe heart failure: bolus injection versus continuous infusion. J Am Coll Cardiol. 1996;28: 376-382.

14. Lahav M, Regev A, Ra'anani P, Theodor E. Intermittent administration of furosemide vs continuous infusion preceded by a loading dose for congestive heart failure. Chest. 1992;102:725-731.

15. Copeland JG, Campbell DW, Plachetka JR, Salmon NW, Larson DF. Diuresis with continuous infusion of furosemide after cardiac surgery. Am J Surg. 1983;146:796.

16. Lawson DH, Gray JMB, Henry DA, Tilstone WJ. Continuous infusion of furosemide in refractory edema. BMJ. 1978;2:476.

17. Allen LA, Turer AT, Dewald T, Stough WG, Cotter G, O'Connor CM. Continuous versus bolus dosing of furosemide for patients hospitalized for heart failure. Am J Cardiol. 2010;105:1794-1797.

18. Aaser E, Gullestad L, Tølløfsrud S, et al. Effect of bolus injection versus continuous infusion of furosemide on diuresis and neurohormonal activation in patients with severe congestive heart failure. Scand J Clin Lab Invest. 1997;57:361-367.

19. Salvador DR, Rey NR, Ramos GC, Punzalan FE. Continuous infusion versus bolus injection of loop diuretics in congestive heart failure. Cochrane Database Syst Rev. 2005;(3):CD003178.

20. Kramer WG, Smith WB, Ferguson J, et al. Pharmacodynamics of torsemide administered as an intravenous injection and as a continuous infusion to patients with congestive heart failure. J Clin Pharmacol. 1996;36:265-270.

21. Licata G, Di Pasquale P, Parrinello G, et al. Effects of high-dose furosemide and small-volume hypertonic saline solution infusion in comparison with a high dose of furosemide as bolus in refractory congestive heart failure: long-term effects. Am Heart J. 2003;145: 459-466.

22. Schuller D, Lynch JP, Fine D. Protocol- guided diuretic management: comparison of furosemide by continuous infusion and intermittent bolus. Crit Care Med. 1997; 25:1969-1975.

23. Cardiovascular Pharmacology Concepts. Diuretics. Available at: http://www.cvpharmacology.com/diuretic/diuretics.htm. Accessed July 22, 2010.

24. Mojtahedzadeh M, Tavakoli Ardakani M, Salehifar E, et al. The relationship between pharmacokinetics variables and pharmacodynamics profiles of bolus versus continuous infusion of furosemide in critically ill patients. J Infus Nurs. 2005;13:127-132.

25. Thomson MR, Nappi JM, Dunn SP, Hollis IB, Rodgers JE, Van Bakel $\mathrm{AB}$. Continuous versus intermittent infusion of furosemide in acute decompensated heart failure. J Card Fail. 2010;16:188-193.

26. Ostermann M, Alvarez G, Sharpe MD, Martin CM. Frusemide administration in critically ill patients by continuous compared to bolus therapy. Nephron Clin Pract. 2007;107:c70-c76.

27. Felker GM, Lee KL, Bull DA, et al; NHLBI Heart Failure Clinical Research Network. Diuretic strategies in patients with acute decompensated heart failure. N Engl J Med. 2011;364:797-805.

28. Moher D, Cook DJ, Eastwood S, Olkin I, Rennie D, Stroup DF. Improving the quality of reports of meta-analyses of randomised controlled trials: the QUOROM statement. Quality of Reporting of Meta-analyses. Lancet. 1999;354:1896-1900.

29. Jadad AR, Moore RA, Carroll D, et al. Assessing the quality of reports of randomized clinical trials: is blinding necessary? Control Clin Trials. 1996;17:1-12.

30. Begg CB, Mazumdar M. Operating characteristics of a rank correlation test for publication bias. Biometrics. 1994;50:1088-1101.

31. Egger M, Davey Smith G, Schneider M, Minder C. Bias in meta-analysis detected by a simple, graphical test. BMJ. 1997;315:629-634.

32. Pivac N, Rumboldt Z, Sardelić S, et al. Diuretic effects of furosemide infusion versus bolus injection in congestive heart failure. Int J Clin Pharmacol Res. 1998;18:121-128.

33. Mojtahedzadeh M, Salehifar E, Vazin A, et al. Comparison of hemodynamic and biochemical effects of furosemide by continuous infusion and intermittent bolus in critically ill patients. Infus Nurs. 2004; $27: 255-261$.

34. Brater DC. Diuretic resistance: mechanisms and therapeutic strategies. Cardiology. 1994;84(suppl 2):57-67.

35. Shankar SS, Brater DC. Loop diuretics: from the Na-K-2Cl transporter to clinical use. Am J Physiol Renal Physiol. 2003;284: F11-F21.

36. Wilcox CS, Mitch WE, Kelly RA, et al. Response to furosemide. I. Effects of salt intake and renal compensation. J Lab Clin Med. 1983; 102:450-458. 